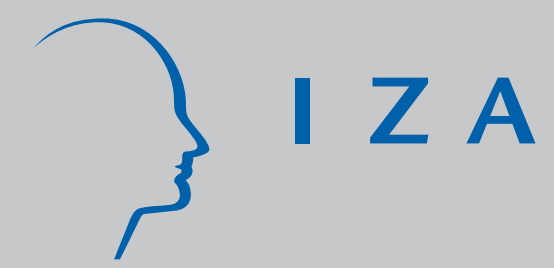

IZA DP No. 8075

Does the Size of the Effect of Adverse Events at High Ages on Daily-Life Physical Functioning

Depend on the Economic Conditions Around Birth?

Robert Scholte

Gerard J. van den Berg

Maarten Lindeboom

Dorly J.H. Deeg

March 2014 


\title{
Does the Size of the Effect of Adverse Events at High Ages on Daily-Life Physical Functioning Depend on the Economic Conditions Around Birth?
}

\author{
Robert Scholte \\ SEO Economic Research \\ Gerard J. van den Berg \\ University of Mannheim, IFAU-Uppsala, VU University Amsterdam and IZA \\ Maarten Lindeboom \\ VU University Amsterdam, Tinbergen Institute, HEB Bergen and IZA
}

Dorly J.H. Deeg

VU University Amsterdam

Discussion Paper No. 8075
March 2014

IZA

P.O. Box 7240

53072 Bonn

Germany

Phone: +49-228-3894-0

Fax: +49-228-3894-180

E-mail: iza@iza.org

Any opinions expressed here are those of the author(s) and not those of IZA. Research published in this series may include views on policy, but the institute itself takes no institutional policy positions. The IZA research network is committed to the IZA Guiding Principles of Research Integrity.

The Institute for the Study of Labor (IZA) in Bonn is a local and virtual international research center and a place of communication between science, politics and business. IZA is an independent nonprofit organization supported by Deutsche Post Foundation. The center is associated with the University of Bonn and offers a stimulating research environment through its international network, workshops and conferences, data service, project support, research visits and doctoral program. IZA engages in (i) original and internationally competitive research in all fields of labor economics, (ii) development of policy concepts, and (iii) dissemination of research results and concepts to the interested public.

IZA Discussion Papers often represent preliminary work and are circulated to encourage discussion. Citation of such a paper should account for its provisional character. A revised version may be available directly from the author. 


\section{ABSTRACT}

\section{Does the Size of the Effect of Adverse Events at High Ages on Daily-Life Physical Functioning Depend on the Economic Conditions Around Birth?*}

This paper considers determinants of physical-functional limitations in daily-life activities at high ages. Specifically, we quantify the extent to which the impact of adverse life events on this outcome is larger in case of exposure to adverse economic conditions early in life. Adverse life events include bereavement, severe illness in the family, and the onset of chronic diseases. We use a longitudinal data set of individuals born in the first decades of the 20th century. The business cycle around birth is used as an indicator of economic conditions early in life. We find that the extent to which functional limitations suffer from the onset of chronic diseases is larger if the individual was born in a recession. The long-run effect of economic conditions early in life on functional limitations at high ages runs primarily via this life event.

JEL Classification: $\quad$ I12, C33, J14

Keywords: functional limitations, long-run effects, business cycle, panel data, health, bereavement, chronic diseases

Corresponding author:

Gerard J. van den Berg

Department of Economics

University of Mannheim

L7, 3-5

68131 Mannheim

Germany

E-mail: vandenberg@uni-mannheim.de

\footnotetext{
${ }^{*}$ We acknowledge permission to use data from the LASA study (which is mostly financed by a longterm grant from the Netherlands Ministry of Health, Welfare and Sports). We thank France Portrait for help with the data, and Tom van Ourti, Rob Alessie and participants at a seminar in Amsterdam and an econometrics conference in Barcelona for useful comments.
} 


\section{Introduction}

The recent literature on late-life health and mortality emphasizes the importance of both (i) early-life conditions (such as nutrition, stress and disease exposure) and (ii) adverse late-life events and shocks. Exposure to adverse conditions early in life may hamper the development of vital organs and the immune system, with irreversible negative effects on health at later ages (Barker, 1994). Long-run effects of adverse conditions may be magnified through poorer health and socioeconomic achievements throughout life (Kuh and Ben-Shlomo, 2004). ${ }^{1}$ At the same time, major life events, like the death of a spouse or a relative, retirement, or the onset of a chronic disease, may affect life quality and economic well-being, and this may lead to psychosocial stress, which in turn may have consequences for subsequent mental and physical health; see e.g. Espinosa and Evans (2008) and Dercon et al. (2005).

The life-course literature postulates that later-life health and responses to shocks are a result of the accumulation of exposure to risk factors throughout life (Kuh and Ben-Shlomo, 2004). The "allostatic load" theory proposed by McEwen and Stellar (1993) argues that a repeated exposure to stressful events has an adverse impact on health, and that individual heterogeneity in the responses to these events is shaped by, among other factors, experiences early in life. Along these lines, the impact of major life events may differ across individuals because of the conditions that individuals have been exposed to early in life.

Our paper advances on this. Our prime interest is in the question whether economic conditions early in life causally impact the causal effect of adverse life events later in life on physical decline later in life. The measure of physical health that we focus on is the extent of functional limitations. Functional limitations affect the ability to perform daily-life activities. They are markers for future disability and long-term care costs (Christensen et al., 2009). They also are an important component of the quality of life (Berkman and Gurland, 1998). Previous studies have found associations between early-life circumstances and functional limitations later in life. Haas (2008) finds a relation between early-life circumstances and the level and progression of functional limitations among adults at or near retirement in the US. Huang et al. (2011) report an association between childhood conditions and functional limitations among Mexican adults.

Concerning the late-life events, we restrict ourselves to the four major shocks that occur most frequently at older ages: the onset or relay of chronic diseases, the death of a spouse, an illness or accident of a partner and the death of other family members. We know

\footnotetext{
${ }^{1}$ See Almond and Currie (2011) for a survey of the economic literature on long-run effects of conditions early in life.
} 
from Van den Berg, Lindeboom and Portrait (2011) that conjugal bereavement affects the probability that the survivor suffers from functional problems in the arthritis spectrum. More generally, adverse late-life events may lead to a change in lifestyle that increases the burden on the body, leading to wear and tear and an irreversible rise in functional limitations. Below we discuss this in more detail.

Of course, conditions early in life may themselves affect the probability of experiencing a major shock later in life. We also consider this in the paper. Moreover, we examine whether conditions early in life have an autonomous direct effect on physical health later in life regardless of the occurrence of late-life events. Figure 1 shows the pathways that link early-life conditions, adverse life events, and the physical health later in life. The dashed arrow represents the interaction effect between early-life conditions and late-life events.

Causal inference is complicated by a number of issues. First, we require an exogenous indicator of early-life conditions that only affects the outcome through its impact around birth (see Van den Berg and Lindeboom, 2014, for a more detailed overview and discussion of these issues). For this we exploit the variation in economic conditions generated by macroeconomic fluctuations around birth, i.e. the stage of the business cycle. These business cycles affect the individual environment but are also most likely independent of suspected confounders. The individuals in our data are born in the Netherlands between 1908 and 1937. This era includes periods of strong economic growth and severe recessions. Secondly, it is likely that life events later in life do not hit individuals randomly but instead depend on unobserved individual factors that also influence health later in life. We exploit the richness of the data in terms of health outcomes and the occurrence of life events, as well as the longitudinal dimension of the data, to control for unobservables that may confound the results, notably by invoking fixed-effect panel data methods. ${ }^{2,3}$

We find that the impact of the life event "the onset or relay of chronic diseases" on functional limitations is larger if the individual was born in a recession. Additional analyses indicate that the long-run effect of economic conditions early in life on functional limitations at high ages runs primarily via this life event. In other words, the long-run effect on functional limitations is primarily an implication of the long-run effect on chronic diseases

\footnotetext{
${ }^{2}$ This methodology is similar to Van den Berg, Lindeboom and Portrait (2010) who focus on cognitive performance among elderly individuals.

${ }^{3}$ An additional issue arises if functional limitations depend on life events in a nonlinear way. In that case, the interaction effect that we are after in a linear panel data analysis may capture this nonlinearity. In our analysis this issue is defined away by restricting attention to binary indicators of early-life conditions and life events. Moreover, notice that regardless of the interpretation of the estimated interaction effect, any nonzero interaction effect is useful as a marker of future functional limitations.
} 
predecessing the functional limitations. In this sense, our results are in agreement with the existing evidence for the developmental origins of cardiovascular diseases and diabetes. To our knowledge, our findings are new in the literature. They complement the recent findings of Van den Berg et al. (2010) who find that a stroke at later ages leads to strong declines in cognitive functioning and that this effect is stronger for those who have experienced adverse economic conditions around birth. The findings are of relevance for public policy as they motivate interventions at the earliest stages of life. Moreover, significant life events are readily observable by aid-workers and are therefore informative on the development of physical health trajectories of cohorts at later ages.

The remainder of the paper is organized as follows. Section 2 describes the data and the variable definitions. This section also contains brief exploratory analyses of the effects of early-life conditions on physical health later in life and the occurrence of adverse events. Section 3 covers the empirical implementation of the model and Section 4 presents the results. Section 5 discusses the results of some robustness checks. Section 6 concludes.

\section{Data description}

\subsection{The LASA data}

The data are from the Longitudinal Aging Study Amsterdam (LASA), an ongoing study that follows a representative sample of the older Dutch population born in 1907-1937. For this study, we use the first 5 waves, held in 1992-1993, 1995-1996, 1998-1999 and 20052006, including 2925, 2204, 1717, 1340 and 932 persons, respectively. We examine panel attrition in Section 3 where we discuss the implementation of the empirical model. ${ }^{4} \mathrm{We}$ deleted incomplete and inconsistent records, leaving us with 2869, 2001, 1571, 1132 and 799 individuals in waves I-V. Table 2 presents an overview of the main health and demographic variables that we use in our analyses.

Health variables Our outcome variable (functional limitations) is an indicator for physical health. It is a common measure for the functioning of older individuals and it is widely used in both health sciences and economics. Functional limitations are measured by selfreports on the ability to perform mobility activities in daily life. These activities include

\footnotetext{
${ }^{4}$ Survey response / attrition figures are presented in Table 1. Most attrition is due to mortality (417, 344, 290 and 355 individuals, respectively). Other reasons for non-response include refusal to cooperate, being too frail to participate in the survey, and loss of contact coordinates. See Deeg et al. (2002) for more information.
} 
the ability to "cut one's own toenails", "to walk up and down 15 steps of a staircase without stopping" and "to use public or private transportation". The total score is the sum of the number of activities that an individual has difficulty performing and ranges thus from 0 (all items can be performed without difficulty) to 3 (the respondent has difficulties with performing all activities). Hence, high values are associated with more functional limitations. Alternatively, we could have analyzed self-reports on the perception of health. However, this measure of health is more sensitive to reporting errors and may, besides true health effects, also reflect differences in reporting styles (Lindeboom and Van Doorslaer, 2004). Furthermore, self-reports may be subject to the "Disability Paradox", the notion that especially in older populations, self-reports on well-being or health remain relatively constant when people age, despite an increase in the prevalence of (chronic) health conditions (Albrecht and Devlieger, 1999). This may obscure the effects of adverse events later in life, which is of prime interest in this study.

The data include information on whether individuals have or have had "chronic diseases". These are: heart diseases, strokes, cancer, respiratory diseases, peripheral artery disease, diabetes and arthritis. Table 2 shows for a steady increase in disease prevalence. Note that by the end of the observation span (Wave '05/'06) disease prevalence rates become substantial. For instance, in that wave two thirds of the sample has arthritis and a bit more than one third has a heart condition.

Sociodemographic variables Age is measured in years. Education is measured in 9 categories, which we aggregate into three categories: lower (elementary not completed, elementary, lower vocational), medium (general intermediate, intermediate vocational, general secondary), higher (higher vocational, college, university). Similarly we group the degree of urbanization of the municipality where the respondent lives from a 5 points scale $(1=$ low, 5 $=$ high) to a three points scale (low, medium, high). The majority of respondents $(64.3 \%)$ is married at the first wave. The variable institutionalized indicates whether the respondent lives in a nursing home. Some variables are included to measure labor market outcomes. These include whether the respondent has a paid job (this includes self-employed) and was a recipient of Disability Insurance (DI) benefits and Early Retirement (ER) benefits. In the last wave all individuals are older than the mandatory pension age for wage earners 65 years) and hence the fraction in DI and ER benefits drops to zero. Net total monthly income is measured in classes (less than 680 euro, 680-1360 euro, 1360-2040 euro, more than 2040 euro). ${ }^{5}$

\footnotetext{
${ }^{5}$ The survey started before the introduction of the euro. The original scale was in classes of 1500 guilders.
} 
Life events Table 3 presents an overview of the frequency of life events occurring between two consecutive waves. We focus in the analyses on four adverse life events. "Chronic diseases" is a grouped indicator of the seven specific diseases listed in Table 2. It records the onset of a new chronic disease or a relay (new event) of a (chronic) condition that one has been diagnosed with before. From the table it can be seen that for instance about 35\% of the respondents face this event between wave 1 and 2 . Death family member corresponds to the death of a parent, sibling, child or grandchild. We also consider the death of a spouse (widowed) and the illness or accident of a partner. These four main groups are events that occur regularly at later ages and have been shown to be important for later-life health (see e.g. Lindeboom et al, 2002). Other, remaining, life events such as the illness or accident of a family member, having a surgery, events associated with labor market outcomes, victim of a crime and conflict with an important person in the life of a respondent are included as controls in the regressions (see Section 3).

Table 4 provides an overview of the within-person development of the physical health outcome that we will use in our analyses: functional limitations. A positive score refers to a deterioration of health. A zero indicates no change and a negative number refers to an improvement in health. The table shows that for a substantial part of the respondents functional limitations do not change between two consecutive waves, but that this number is declining over waves (i.e. as people age). Furthermore, the share of positive scores is larger than the share of negative scores, implying deteriorations in functional mobility.

\subsection{Macroeconomic information}

We use the stage of the business cycle at the moment of birth as a feasible indicator for economic conditions early in life. The data are measured annually. They are informative of household conditions, notably in the first half of the twentieth century when welfare states were not as developed as they currently are. Our birth cohort window includes the severe recession around the end of World War I and during the Influenza pandemic, i.e. the years 1917 and 1918 (Vugs, 2002). The Dutch economy developed positively alongside a global economic upturn in the 1920s which resulted in an increase of average living standards. This was followed by the Great Depression, which arrived relatively late in the Netherlands (1931) and lasted long (until 1936). The delayed arrival of economic recovery was partially caused by the refusal of the Dutch government to drop the gold standard. Indeed, the Great Depression has had substantial impact on the daily life of civilians, illustrated by a 729 percent increase in the number of unemployed persons between 1929 and 1936 and substantial poverty (Beishuizen and Werkman, 1968). 
The historical trends referred to above are reflected in fluctuations in the GDP for these years. Figure 2 shows the detrended GDP series. ${ }^{6}$ In our analyses we will use this detrended cyclical component instead of the actual level of GDP in order to control for secular improvements in GDP over time. For the detrending we applied a Hodrick-Prescott filter with smoothing parameter 500 to decompose log annual per capita GDP into a trend and a cyclical component (Hodrick and Prescott, 1997). ${ }^{7}$

The figure shows that we can split our sample period into two cycles of a boom and a subsequent recession, i.e. Cycle I: 1909-1921 (boom: 1909-1913 and recession: 1914-1921) and Cycle II: 1924-1936 (boom: 1924-1930 and recession: 1931-1936). In our analyses we will use those respondents born in either of these two cycles and omit other observations (i.e. 1908, 1922, 1923 and 1937). In the main analyses we use a binary indicator for a recession at birth that equals one when log GDP is below its trend level and zero otherwise. Next, in robustness checks, we use the value of the cyclical component instead of the binary indicator. This variable takes the size of the booms and recessions into account. In that section we also use a dummy variable that corresponds to the troughs of the business cycles, defined as the lowest $25 \%$ of the cyclical indicators of each cycle. ${ }^{8}$

\subsection{Basic analyses of long-run effects}

We start by investigating effects of a birth in a recession on the physical health stock later in life. The health stock is measured by the number of functional limitations. We conduct these analyses by performing simple (ordered probit) regressions where we relate the circumstances in the year of birth to physical health later in life. We do this separately for Cycle I and Cycle II (see above for a definition), because of the different nature of both cycles. For these regressions we use all waves. Recall that between Wave I and V a substantial share of the sample is lost due to attrition. To correct for this we include variables that indicate whether an individual will leave the sample in a future wave. We include separate indicators for each wave and make a distinction between the reasons for leaving the sample: attrition due to mortality and attrition for other reasons. Besides these attrition indicators these regressions also include our variable of interest, i.e. an indicator

\footnotetext{
${ }^{6}$ See Maddison (2003) for the macroeconomic data.

${ }^{7}$ We discuss the sensitivity of the results to the selected value of the smoothing parameter in the robustness analyses (Section 5).

${ }^{8}$ Our method requires the absence of compositional differences between cohorts of individuals born in booms and recessions. Van den Berg et al. (2011) consider this with using information on household characteristics in our data, and they examine such differences. Their findings are in agreement with the assumption.
} 
whether the individual is born in a recession, and age (minus 55 years) and gender.

The results of these pooled regressions are reported in Table 5. A positive coefficient is associated with more functional limitations. From the table one can see that those born in a recession have a lower physical health stock later in life. This holds for both cycles $(\beta=0.219$ and $\beta=0.301) .^{9}$

Table 6 presents the results of a model that extends the previous analyses by also including controls for the adverse life events occurring in the preceding period and a more background characteristics. Inclusion of these additional regressors has little impact on the effect of a recession at birth on functional limitations later in life $(\beta=0.193$ and $\beta=0.275)$. Concerning the adverse life events, we find that significant effects of the onset or relay of chronic diseases (botyh cycles) and the illness or accident of a partner (Cycle II). The estimates of widowed and the death of a family member are insignificant. Finally, the results for the background characteristics are as expected. The positive age coefficients indicate that the number of functional limitations is increasing in age. The negative coefficients for education, gender and marriage indicate that the number of limitations is lower for males, those with higher education levels and those who are married. ${ }^{10}$

We conclude that a birth in adverse economic times leads to a lower physical health stock later in life. This finding is in line with the literature on long-run effects of conditions early in life on later life mortality and morbidity (see Section 1).

We estimate similar models for the occurrence of each of the adverse events that we consider in our study: the onset of a (new) chronic disease (or the relay of an existing condition); the death of a partner; an illness or accident of a partner; the death of family member. The outcome variables are indicators for the occurrence of a shock between two waves. Like in the previous analyses, we estimate the models per cycle and include besides the indicator for birth in a recession, attrition dummies and age and gender. Table 7 reports the coefficients of probits for the probability and a positive coefficient indicates a higher probability of experiencing the event.

Table 7 shows that all, except for one, coefficients indicating a birth in a recession are insignificant and the single significant coefficient has a sign that is opposite to what we

\footnotetext{
${ }^{9} \mathrm{~A}$ joint regression indicates that the effects of a birth in a recession are not statistically different for cycle I and II.

${ }^{10}$ This analysis does not control for chronic diseases originating at earlier stages. The effects of the onset or relay of chronic diseases remain significant, when conducting an extended regression that includes a dummy for the presence of one or more chronic diseases in earlier waves. The estimates of a recession at birth on functional limitations are smaller (and insignificant for Cycle I) in this extended specification. This indicates that part of the impact of a recession at birth on the later-life physical health stock occurs through the effects of chronic diseases.
} 
expect; those born in the recession of Cycle II become widowed less often $(\beta=-.284)$. Inspection of the data revealed that the probability of becoming widowed increases rapidly with age. Both cycles start with a boom and a subsequent recession, implying that those born in a recession are younger. This aging effect is picked up by our recession indicator. Indeed, including a more flexible specification of the age effects leads to a smaller and insignificant coefficient of the recession indicator.

\section{Specifications of the full model with interaction ef- fects}

The key features of our model framework are summarized in Figure 3. As hypothesized in the introduction and confirmed by various papers in the literature, those who have been exposed to adverse conditions early in life are likely to have worse health later in life. The previous section also confirmed this for functional limitations. It is conceivable that these individuals also respond differently to adverse major events later in life, because their health position at the onset of the life event is poorer, or because they lack the financial and social means to cushion the impact of these shocks.

We briefly discuss why the four life events we consider may be expected to lead to functional limitations. Regarding chronic diseases, the basic idea is that the diseases are the start of paths that lead from the initial impairment in health (chronic diseases) to a decrease in the capacity to perform daily life activities (functional limitations). We refer to Verbrugge and Jette (1994) for an elaborate discussion of such paths. Conjugal bereavement is commonly related to an increase in mortality. See, for instance, a recent meta-study by Shor et al. (2012). It may also have a large effect on informal care which is an important part of long-term care for older people. Moreover, spouses are important for the compliance to prescriptions of medicine uptake and visits to the doctor when necessary. As a result, becoming widowed may have a negative impact on health. The death of a spouse causes arthritis (which may have an effect on functional limitations), psychosocial stress, depressions and anxiety (Van den Berg et al., 2011). There is evidence that it is also associated with feelings of loneliness, a loss of social network and poverty. Deaths of family members may be detrimental for health in comparable ways (Lindeboom et al., 2002). The illness or accident of a partner may have an additional effect on health through an increased demand for informal care.

Our empirical model is a fixed effects panel data model: 


$$
H_{i t}=c_{i}+\mathbf{X}_{i t}^{\prime} \beta+u_{i t}, t=1 \ldots . T, i=1 \ldots . N
$$

where $H_{i t}$ is later-life health of individual $i$, at time period $t . c_{i}$ is a time-constant individual specific effect, $x_{i t}$ is a vector of $k$ individual specific determinants at time $t$, including adverse early-life conditions and major life events. $u_{i t}$ represents the idiosyncratic individual shock. It is well known that one can eliminate the 'nuisance parameters' $c_{i}$ by taking the first difference of (1):

$$
\Delta H_{i t}=\Delta \mathbf{X}_{i t}^{\prime} \beta+\Delta u_{i t}, t=2 \ldots . T, i=1 \ldots . N .
$$

with $\Delta$ being the first-difference operator $\left(\Delta y_{i t}=y_{i t}-y_{i t-1}\right) . \Delta X_{i t}$ now includes indicators of life events occurring between two measurement moments $t$ and $t$-1. Note that first differencing, on the other hand, also eliminates all variables that remain constant over time, such as the variable indicating whether the respondent is born in a recession. This first differencing of (1) is convenient as it eliminates the dependence between the included regressors and the fixed part of the composite error term $c_{i}+u_{i t}$. Moreover, this fixed effects specification controls for possibly selective attrition as long as this process is driven by fixed individual factors (the $c_{i}$, see e.g. Lindeboom et al., 2002). This is particularly relevant here as 1406 out of the original 3107 respondents $(\approx 45 \%)$ are observed to die between waves I-V. This kind of attrition is of course (leaving non-health related accidents aside) related to health. Differencing the data may not eliminate all correlation between the included regressors and the stochastic error term due to attrition (i.e. selective attrition effects may work via $u_{i t}$ ). A pragmatic way to deal with this in the context of a linear model is to include a dummy for each specific subsample of respondents participating in a range of consecutive waves. These sample dummies attempt to capture the relevant correlation between observable and unobservable variables that remain after taking first differences. Of course, including attrition dummies and taking first differences may still not be enough to eliminate the dependence between the transitory shock $\left(u_{i t}\right)$ and the included regressors $\left(x_{i t}\right)$ in equation (1). Our approach is to exploit the richness of our LASA data and to include as many time varying determinants (observed shocks) as possible. We are in the fortunate position to have access to data that observe a large number of events like moves to institutions, surgeries, being victim of a crime, conflict with important persons in the life of the respondent etc (see Table 3 for an overview of these variables and their means). Of course these are life events in their own right.

The parameter of interest is the interaction term between the cyclical indicator at birth and the life event shock. Concerning the indicator of the cyclical conditions at birth, in the 
main analyses we use a dummy indicating a recession in the year of birth. In the robustness analyses, we vary the indicator of business cycle conditions and include also the value of the cyclical component of the HP-filter and a dummy indicating the troughs of the recessions (defined as the lowest $25 \%$ of the cyclical indicators of each cycle).

Note that in this paper we exploit life events occurring in the period between the previous and the current wave of the panel survey. The time span may in some situations be too short to take the full effects of these events into account. Effects that mature slowly over time may be important as well, but dealing with this is beyond the scope of this study. Also note that some of the life events we consider may mutually affect each other. For example, bereavement may increase the likelihood of chronic diseases. As a consequence, part of the effects of these life events may be captured by the onset of chronic diseases.

\section{Estimation Results}

Table 8 shows the results of the first-differences panel data model. The regression includes interactions between the indicator for a recession at birth and the four major adverse life events. We also include controls for age, age ${ }^{2}$, the remaining life events, a constant and wave and sample dummies in the regressions but these estimates are omitted from the table. Age refers to the age of an individual minus 55 years. The remaining life events are a labor market transition, i.e. the loss of a paid job or new recipience of disability or early retirement benefits, financial problems, surgery, illness or accident of a remaining family member, a conflict with a person deemed important and being victim of criminal activities. The financial problems variable is an interesting adverse shock by itself but its frequency is too low to identify precise effects. The sample dummies are binary variables indicating the number of waves that someone is present in the sample. These dummies along with the rich set of controls aim to capture the correlation between the included variables and unobserved heterogeneity that remains present after taking first differences. The wave dummies are included to control for time effects. High values of the outcome variable imply more functional limitations and are therefore associated with low health levels. Therefore, positive estimates point at a deterioration of health in our model.

The results in Table 8 show that there is a significant effect of chronic diseases on the number of functional limitations $(\beta=0.086)$. The positive coefficient implies that the number of functional limitations is larger after the onset or relay of chronic diseases. The signs of the other three adverse life events also point at effects on health but they are all insignificant. The interaction effect between chronic diseases and a recession at 
birth is significant as well. This result indicates that the effect of the onset of chronic diseases is larger after a birth in a recession implying that the effects of chronic diseases on functional limitations are exacerbated by adverse early-life conditions $(\beta=0.105)$. None of the remaining interaction effects are significant. It is not straightforward to interpret the estimate of the interaction between early-life conditions and the onset of chronic diseases in terms of an effect size, due to the categorical nature of the outcome variable: a 0 score corresponds to zero functional limitations, while a score of respectively 1, 2 or 3 indicates the number of the three activities that is conducted with difficulty. Nevertheless, a point estimate of 0.11 is substantial given the mean score of 0.85 .

Next, in order to examine whether the results differ per gender, we re-estimate the firstdifferences panel data model separately for males and females. The results are shown in Table 9. The coefficients of chronic diseases and their interactions with a recession at birth in these restricted samples are comparable to the ones in Table 8. However, the standard errors are larger. This is likely to be due to the reduction in sample sizes. The separate analyses also indicate that widowed and the death of a family member are insignificant and that the illness or accident of a partner is significant for males, but not for females. Table 8 shows that this latter estimate is insignificant when analyzing both genders jointly.

We calculate the fixed effects of this model by subtracting for each individual the average of the predicted values resulting from the main regressions of Table 8 from the average of the observed values of the outcome variables, i.e. $\hat{c}_{i}=\bar{H}_{i}-\overline{\mathbf{X}}_{i}^{\prime} \hat{\beta}$ (See for instance Wooldridge, 2010). Next, we regress these fixed effects on a binary indicator for a recession at birth and a range of background characteristics, which are the year of birth, education, gender, marital state, the urbanization rate and an indicator for the presence of a chronic disease in the first wave. The results for this exercise are shown in Tables 10. Recall that positive values are associated with more functional limitations and hence worse health.

The coefficients of the background characteristics are as expected. The year of birth variables indicate that the ones born later have lower numbers of functional limitations. Higher educated and married individuals also have less functional limitations. Furthermore, males have better physical health than women and the presence of a chronic disease in the first wave has a negative effect on the health outcome. Finally, there is no significant effect of the urbanization rate of the municipality of residence.

The positive coefficient of the variable indicating a recession at birth implies that the ones who are born in adverse economic conditions have lower physical health later in life. However, this estimate is insignificant. Combining this result with the findings from Table 5 (i.e. there are long-run effects of being born in a recession) and Table 8 (i.e. the effects of shocks are magnified after a birth in a recession) indicates that the effects of a recession 
at birth on physical health later in life primarily runs via the effect of major adverse life events later in life. The question remains how important this effect is in the total impact of a birth in a recession on later-life physical health (functional limitations). In order to answer this question one needs to compare the marginal effects of the results (Table 5) with the coefficients of the interaction effect between chronic diseases and a recession at birth in Table 8. The marginal effects of the health stock equation (corresponding Table 8 ) are 0.204 for Cycle I and 0.205 for Cycle II, respectively. Hence, the effect of a shock for those born in a recession accounts for larger part of the total long-run effect (cf. $(0.86+0.105)$ with 0.205). This implies that the magnified impact of the onset or relay of chronic diseases after a birth in a recession is an important contributor to the long-run relation between a birth in an adverse economic environment and physical health later in life.

\section{Robustness analyses}

We start this robustness analysis by adopting alternative indicators of economic conditions at birth. First, we use the value of the cyclical component of the HP-filters instead of the binary indicator for a recession at birth in Table 11. The value of the cyclical part of the HP-filters is the difference between the actual GDP level and the trend component. This cyclical component is strongly dependent on the chosen value of the smoothing parameter. We select, in agreement with Van den Berg et al. (2006), a value of 500 in the main analyses. The inclusion of the cyclical part of the HP-filters in the analyses is informative because it takes the magnitude of the cyclical term into account, albeit at the expense of a higher sensitivity to imprecisely recorded historical GDP levels. For this latter reason, we prefer the original specification adopting binary indicators for clear recessions that are shown in Figure 2. Second, we include interactions with a dummy corresponding to the troughs of the business cycles in Table 12. A trough is defined as the lowest quartile of the cyclical indicators of each business cycle. This variable aims to capture that the effects may be strongest in the most severe part of the recessions. A birth in a recession or trough of a business cycle corresponds to a negative cyclical value of the HP-filter. Therefore, the signs of the interactions with the business cycle indicators in, on one hand, Tables 8 and 12 and, on the other hand, Table 11 are in the opposite direction. Recall that positive estimates are associated more functional limitations. Hence, a negative interaction between a life event and the cyclical value of the HP-filter indicates a magnifying effect of poor conditions early in life, whereas the opposite holds for interactions between life events and the binary indicators for a birth in a recession or the trough of a cycle. Next, 
we examine the sensitivity of the results to modifications in the analyses of the business cycles by varying the values of the smoothing parameters. The results of these analyses are shown in Table 13. This is relevant because the recessions in the main analyses are determined on the basis of the cyclical values of the HP-filters, which are driven by this parameter. The values are varied from 500 in the main analyses to 250, 100 and 50. The time series of the cyclical component of log GDP that follow from these varying smoothing parameters are shown in Figure 4. Subsequently, the samples of individuals are adjusted on the basis of these modified analyses implying that the individuals who are not born in a clear cycle are left out of the analyses. Finally, one may be concerned that the estimates of the interactions between the major life events and recessions at birth are confounded by age-related effects, although we control for age and age ${ }^{2}$. Therefore, we re-estimate the main regressions of Table 8, while including interactions between the binary indicator for a recession at birth and the age indicators. ${ }^{11}$

The sensitivity analyses including the alternative indicators of economic conditions at birth in Tables 11 and 12 both indicate that the effects of chronic diseases on functional limitations are larger after a birth in an adverse economic environment. These findings are in line with the results from the main regressions in Table 8 . The estimates of the interactions between the onset or relay of chronic diseases and the value of the cyclical component of the HP-filter or the binary indicator for a birth in the trough of a cycle are both significant. The magnitude of the estimate of the interaction between chronic diseases and a birth in the trough of a cycle in Table 12 is larger than the interaction with a birth in a recession in Table 8. This finding is in line with the notion that the effects may be strongest in the most severe part of the recessions. Table 11 also provides some evidence of an interaction between the death of a family member and the stage of the business cycle at birth, but in the opposite direction from our expectations. This effect is significant at the $10 \%$ level and is rather small. Figure 2 shows that the cyclical indicator varies between roughly .1 and -.2. So at the deepest point of the cycle, the estimate of .482 corresponds to an effect of roughly 0.12 on a variable that can take on values between 0 and 3 (with mean 0.85). Tables 8 and 12 also provide different results. Next, we re-estimate the main model when varying the values of the smoothing parameter of the HP-filters. These results are shown in Table 13. The interactions between the onset or relay of chronic diseases and a recession at birth remain significant and indicate that the health impact of this event is larger after a birth in a poor economic environment early in life. The remaining interactions between the major events and the indicator for a recession at birth are all insignificant. This

\footnotetext{
${ }^{11}$ The results from the final regression are omitted but available upon request.
} 
indicates that the interaction effect between economic conditions at birth and the death of a family member is strongly dependent on the exact specification of the HP-filters. Finally, the significant interaction between chronic diseases and economic conditions early in life also does not seem to be confounded by age effects. The inclusion of interactions between the age indicators and a recession at a birth in the main analysis of Table 8 does not have a significant impact on the results. We conclude on the basis of these analyses that our earlier findings are robust to alternative specifications.

We also estimated a version of Table 8 where we include separate indicators for the different chronic conditions. This is done to identify which particular conditions are driving the main empirical finding.

The results of this exercise are shown in Table 14. Surprisingly, the effects of peripheral artery diseases are smaller for those individuals who are born in a recession. This estimate is significant at $10 \%$. The results also indicate that the effects of arthritis and cancer are significantly larger after a birth in a recession. This indicates that these two diseases are underlying the exacerbated impact of the onset or relay of chronic diseases on functional limitations in the previous analyses.

\section{Discussion and conclusions}

This paper focuses on the influence of economic conditions early in life on the impact of adverse life events on physical health later in life. We take the endogenous nature of economic conditions into account by using the stage of the business cycle at birth as an instrument for economic conditions early in life. Panel data estimators, which exploit the longitudinal structure of the data, identify direct effects of life events and indirect effects between these events and economic conditions early in life on functional limitations later in life. The endogenous nature of these life events is dealt with by allowing for unobserved individual fixed effects and including a broad range of controls. Furthermore, we provide descriptive analyses to investigate whether there are direct effects of economic conditions early in life on physical health and the probability of facing adverse shocks at later ages.

The most important finding of our main (panel data) analysis is that the impact of the onset or relay of chronic diseases on the number of functional limitations is larger for those born during a recession. This implies that adverse economic conditions at birth exacerbate the impact of adverse shocks later in life. This effect is substantial in size.

We find that a recession in the year of birth affects the later-life physical health stock of the respondents. However, when we regress the individual fixed effects from the panel data 
analysis on the recession indicator and a range of individual characteristics then we do not find a direct effect of economic conditions early in life. Jointly, these results imply that a birth during an economic recession has a long-run impact on physical health (functional limitations), but that this is primarily via a larger impact of an adverse event (onset or relay of chronic diseases). Stated differently, the impact of a poor early-life environment becomes apparent in functional limitations only upon the occurrence of adverse life events at high ages.

We do not find significant effects of bereavement or illness or accident of a partner on functional limitations. Other studies have reported effects of these events on mortality and hospitalization but clearly those outcome variables differ from functional limitations. Some effects may only become apparent after a longer period of time, for instance through the loss of the zest for life. Furthermore, part of the effects on functional limitations may run through the onset of chronic diseases for which we control in the regressions.

Our findings are in agreement with the "life course" and "allostatic load" theories of long-run effects on health outcomes. The results point at the importance of early-life conditions and provide a justification for a focus of public policy on the earliest stages in life. Moreover, significant life events are readily observable by aid-workers and are therefore informative on the development of physical health trajectories of cohorts at later ages. 


\section{References}

Albrecht, G.L., Devlieger, P.J. (1999). The Disability Paradox: high quality of life against all odds, Social Science and Medicine 48(8): pp. 977-988.

Almond, D. and Currie, J. (2011). Killing me softly: The fetal origins hypothesis, Journal of Economic Perspectives 25, 153-172.

Barker, D.J.P. (1994). Mothers, babies, and disease in later life. British Medical Journal Publishing Group: London.

Beishuizen, J. and Werkman, E. (1968). Nederland in de Crisistijd 1932-1939. A.W. Slijthof: Leiden.

Berkman, C.S. and Gurland, B.J. (1998). The relationship among income, other socioeconomic indicators, and functional level in older persons, Journal of Aging and Health 10(1): pp. 81-98.

Christensen, K., Doblhammer, G., Rau, R. and Vaupel, J.W. (2009). Ageing populations: the challenges ahead, Lancet 374(9696): pp. 1196-1208.

Deeg, D.J.H., Van Tilburg, T., Smit, J.H. and De Leeuw, E.D. (2002). Attrition in the Longitudinal Aging Study Amsterdam: the effect of differential inclusion in side studies, Journal of Clinical Epidemiology 55(4): pp. 319-328.

Dercon, S., Hoddinott, J. and Woldehanna, T. (2005). Vulnerability and shocks in 15 Ethiopian villages, 1999-2004, Working paper, CRSP, Madison.

Espinosa, J. and Evans, W.N. (2008). Heightened mortality after the death of a spouse: Marriage protection or marriage selection?, Journal of Health Economics 27(5): pp. $1326-1342$.

Haas, S. (2008). Trajectories of functional health: The 'long arm' of childhood health and socioeconomic factors, Social Science and Medicine 66(4): pp. 849-861.

Hodrick, R. and Prescott, E.C. (1997). Postwar U.S. business cycles: an empirical investigation, Journal of Money, Credit and Banking 29(1): pp. 1-16.

Huang, C., Soldo, B.J. and Elo, I.T. (2011). Do early-life conditions predict functional health status in adulthood? The case of Mexico, Social Science and Medicine 72(1): pp. 100-107.

Kuh, D. and Ben-Shlomo, Y. (2004). A life course approach to chronic disease epidemiology, 2nd edition. Oxford University Press: Oxford. 
Lindeboom, M., Portrait, F. and Van den Berg, G.J. (2002). An econometric analysis of the mental-health effects of major events in the life of older individuals, Health Economics 11(6): pp. 505-520.

Lindeboom, M. and Van Doorslaer, E. (2004). Cut-point shift and index shift in selfreported health, Journal of Health Economics 23(6): pp. 1083-1099.

Maddison, A. (2003). The world economy: historical statistics. Development Centre Studies, OECD Publishing: Paris.

McEwen, B.S. and Stellar, E. (1993). Stress and the individual. Mechanisms leading to disease, Archives of Internal Medicine 153(18): pp. 2093-2101.

Shor, E., Roelfs, D.J., Curreli, M., Clemow, L., Burg, M.M. and Schwartz, J.E. (2012). Widowhood and mortality: a meta-analysis and meta-regression, Demography 49(2): pp. 575-606.

Van den Berg, G.J., Deeg, D.J.H., Lindeboom, M. and Portrait, F. (2010). The role of early-life conditions in the cognitive decline due to adverse events later in life, Economic Journal 120(548): pp. 411-428.

Van den Berg, G.J., Doblhammer, G. and Christensen, K. (2011). Being born under adverse economic conditions leads to a higher cardiovascular mortality rate later in life: evidence based on individuals born at different stages of the business cycle, Demography 48(2): pp. 507-530.

Van den Berg, G.J., Lindeboom, M. and Portrait, F. (2006). Economic conditions early in life and individual mortality, American Economic Review 96(1): pp. 290-302.

Van den Berg, G.J., Lindeboom, M. and Portrait, F. (2011). Conjugal bereavement effects on health and mortality at advanced ages, Journal of Health Economics 30(4): pp. 774-794.

Van den Berg, G.J. and Lindeboom, M. (2014). Aging: conditions early in life and health and mortality at advanced ages, in: T. Culyer, ed., Encyclopaedia of health economics (North-Holland, Amsterdam).

Verbrugge, L.M. and Jette, A.M. (1994). The disablement process, Social Science and Medicine 38(1): pp. 1-14.

Vugs, R. (2002). In veel huizen wordt gerouwd. De Spaanse griep in Nederland. Aspekt: Soesterberg.

Wooldridge, J. (2010). Econometric analysis of cross section and panel data, 2nd edition. MIT press: Cambridge. 


\section{Appendix}

Figure 1: Early-life conditions, adverse life events and later-life physical health

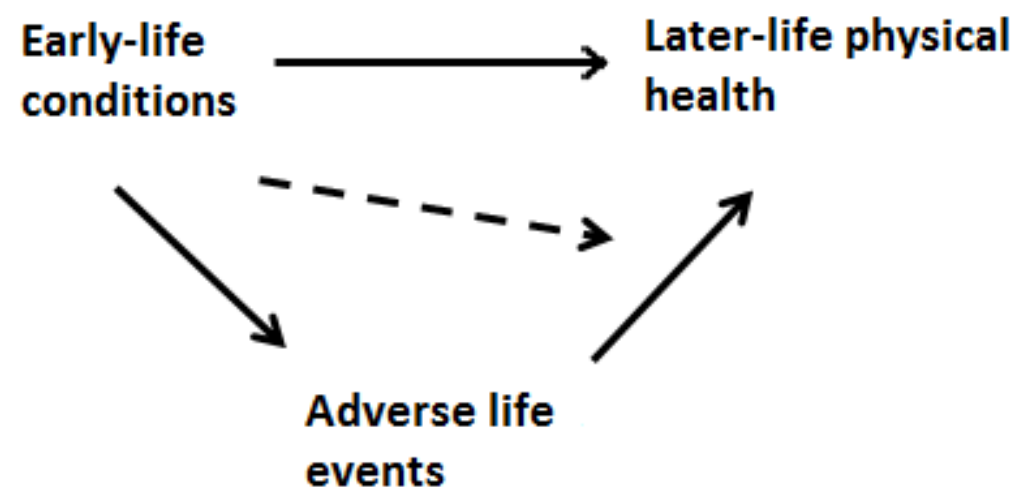


Figure 2: The cyclical part of log GDP in the years of birth of respondents

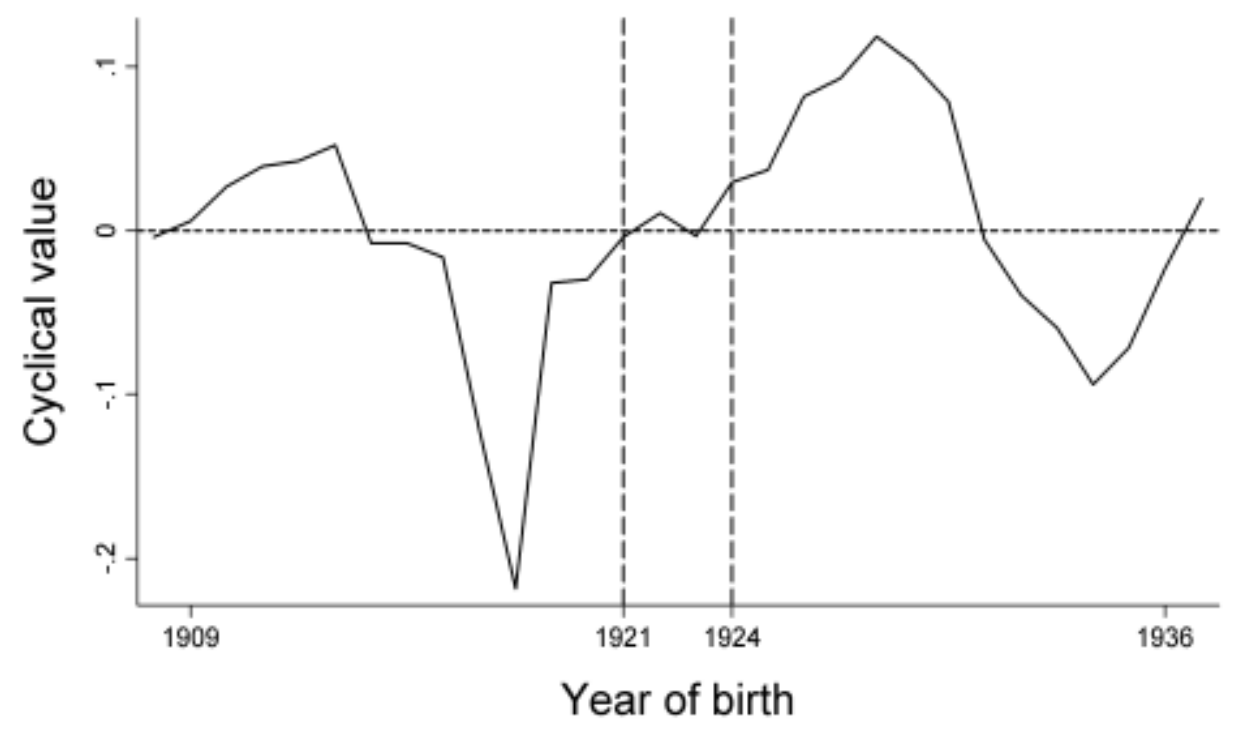

Figure 3: The magnifying effect of early-life conditions on the impact of an adverse life event

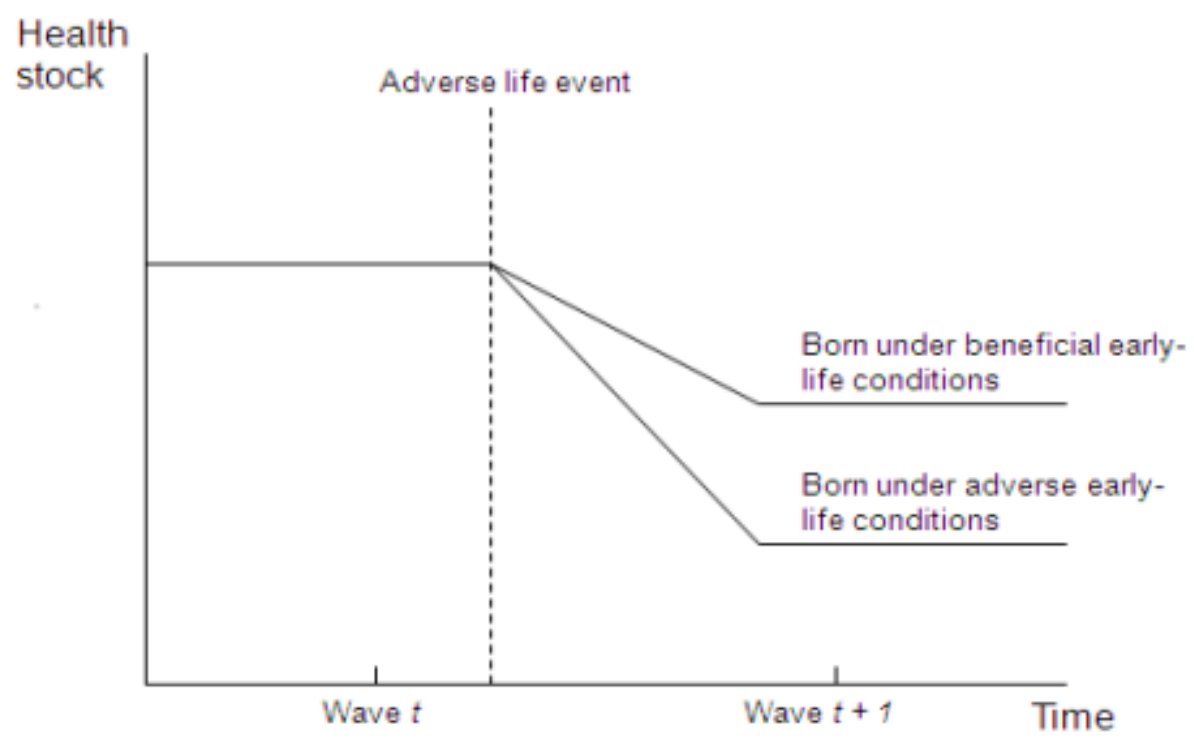


Figure 4: The cyclical part of log GDP for different values of the smoothing parameter
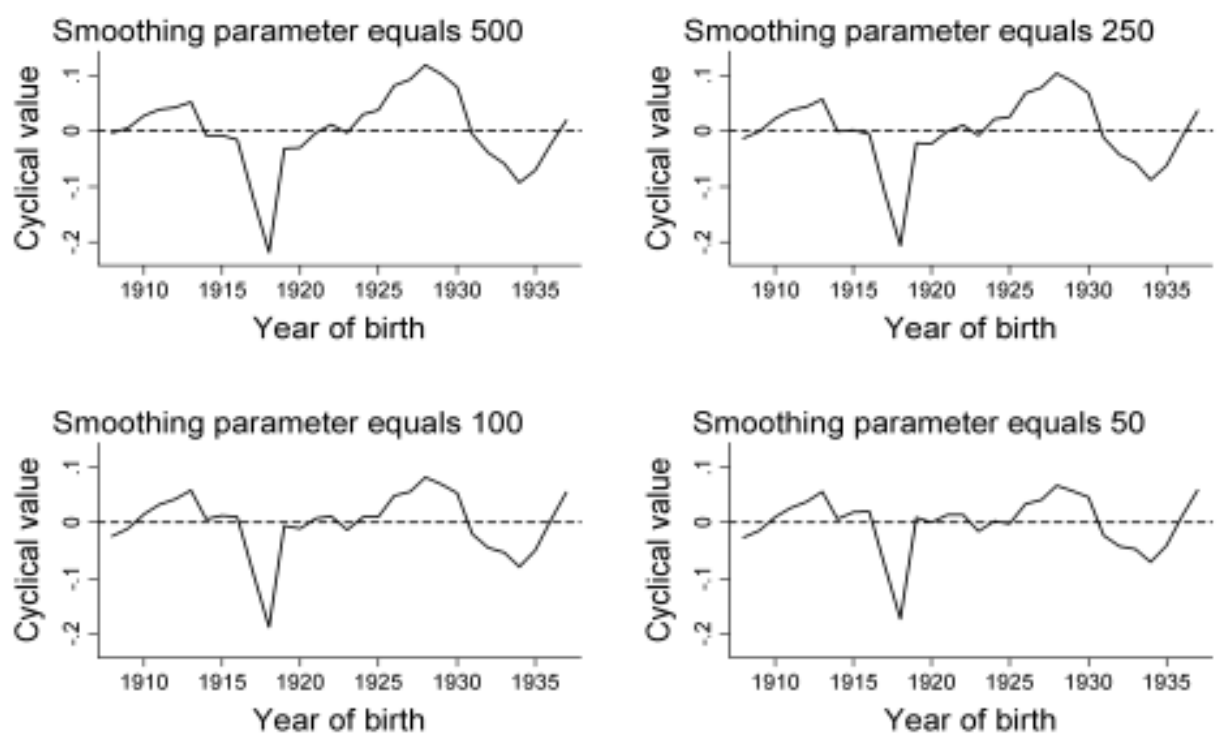

Table 1: Specification of the non-response in the LASA dataset

\begin{tabular}{lccccc}
\hline \hline & & \multicolumn{3}{c}{ Wave } \\
& I & II & III & IV & V \\
\hline Number of individuals & 2925 & 2204 & 1717 & 1340 & 932 \\
Deceased & & 417 & 344 & 290 & 355 \\
Short interviews & 182 & 98 & 157 & 134 & 115 \\
Refusals & & 145 & 125 & 95 & 79 \\
Interview by telephone & & 243 & 202 & 217 & 210 \\
Attrition between previous waves & & & 562 & 1031 & 1416 \\
\hline Total & 3107 & 3107 & 3107 & 3107 & 3107 \\
\hline \hline
\end{tabular}


Table 2: Mean frequencies of relevant variables

\begin{tabular}{|c|c|c|c|c|c|c|}
\hline & Score & $\begin{array}{l}\text { Wave } \\
\text { '92/'93 }\end{array}$ & $\begin{array}{c}\text { Wave } \\
\text { '95/'96 }\end{array}$ & $\begin{array}{l}\text { Wave } \\
\text { '98/'99 }\end{array}$ & $\begin{array}{c}\text { Wave } \\
\text { '01/'02 }\end{array}$ & $\begin{array}{c}\text { Wave } \\
\text { '05/'06 }\end{array}$ \\
\hline Functional & 0 limitations & 60.4 & 51.5 & 47.6 & 42.1 & 35.2 \\
\hline \multirow[t]{3}{*}{ limitations } & 1 limitations & 18.9 & 23.1 & 22.9 & 25.8 & 24.7 \\
\hline & 2 limitations & 11.3 & 12.7 & 16.2 & 19.3 & 25.9 \\
\hline & 3 limitations & 9.4 & 12.6 & 13.4 & 12.8 & 14.3 \\
\hline \multicolumn{7}{|l|}{ Chronic Diseases } \\
\hline Respiratory & yes & 11.2 & 13.6 & 15.7 & 16.3 & 17.4 \\
\hline Heart & yes & 19.7 & 23.1 & 27.1 & 30.1 & 34.3 \\
\hline Peripheral artery & yes & 9.7 & 11.6 & 12.6 & 14.9 & 15.1 \\
\hline Diabetes & yes & 7.6 & 7.6 & 9.7 & 11.4 & 13.8 \\
\hline Stroke & yes & 5.1 & 6.8 & 7.0 & 8.4 & 10.1 \\
\hline Arthritis & yes & 35.0 & 46.6 & 52.1 & 57.2 & 63.6 \\
\hline Cancer & yes & 8.9 & 11.1 & 14.3 & 15.0 & 19.7 \\
\hline \multicolumn{7}{|l|}{ Sociodemographics } \\
\hline Age & & 70.3 & 72.2 & 73.7 & 74.8 & 76.9 \\
\hline Gender & male & 48.6 & 47.2 & 46.3 & 45.8 & 43.3 \\
\hline \multirow[t]{3}{*}{ Education } & lower & 62.6 & 60.9 & 58.8 & 58.1 & 53.7 \\
\hline & middle & 25.7 & 26.8 & 28.7 & 28.9 & 33.4 \\
\hline & higher & 11.6 & 12.3 & 12.5 & 13.0 & 12.9 \\
\hline \multirow[t]{3}{*}{ Urbanization } & low & 12.9 & 12.3 & 12.9 & 14.4 & 14.3 \\
\hline & middle & 27.4 & 27.0 & 28.1 & 27.8 & 27.9 \\
\hline & high & 59.8 & 60.6 & 58.9 & 57.8 & 57.8 \\
\hline \multirow[t]{4}{*}{ Marital status } & never married & 5.5 & 4.2 & 3.6 & 2.7 & 2.9 \\
\hline & married & 64.3 & 60.0 & 58.8 & 58.4 & 59.3 \\
\hline & divorced & 5.1 & 5.6 & 5.7 & 5.1 & 4.8 \\
\hline & widowed & 25.1 & 30.3 & 31.9 & 33.8 & 33.0 \\
\hline Institutionalized & yes & 2.4 & 3.3 & 2.9 & 2.7 & 2.3 \\
\hline Paid job & yes & 12.4 & 8.2 & 6.1 & 5.7 & 4.8 \\
\hline Disability insurance recipience & yes & 7.6 & 1.2 & 0.8 & 0.1 & 0.0 \\
\hline \multirow[t]{3}{*}{ Early retirement recipience } & no & 92.8 & 96.5 & 97.6 & 99.1 & 100.0 \\
\hline & yes, partly & 0.9 & 0.6 & 0.8 & 0.1 & 0.0 \\
\hline & yes, completely & 6.3 & 3.0 & 1.7 & 0.8 & 0.0 \\
\hline \multirow[t]{5}{*}{ Income } & missing & 10.8 & 6.2 & 5.5 & 5.8 & 7.0 \\
\hline & $<680$ & 19.9 & 14.8 & 10.2 & 2.0 & 1.4 \\
\hline & $680-1.360$ & 45.1 & 47.1 & 46.8 & 44.0 & 31.4 \\
\hline & $1.360-2.040$ & 15.8 & 20.3 & 22.4 & 28.8 & 31.5 \\
\hline & $>2.040$ & 8.3 & 11.6 & 15.1 & 19.4 & 28.7 \\
\hline Sample Size & & 2869 & 2001 & 1571 & 1132 & 799 \\
\hline
\end{tabular}




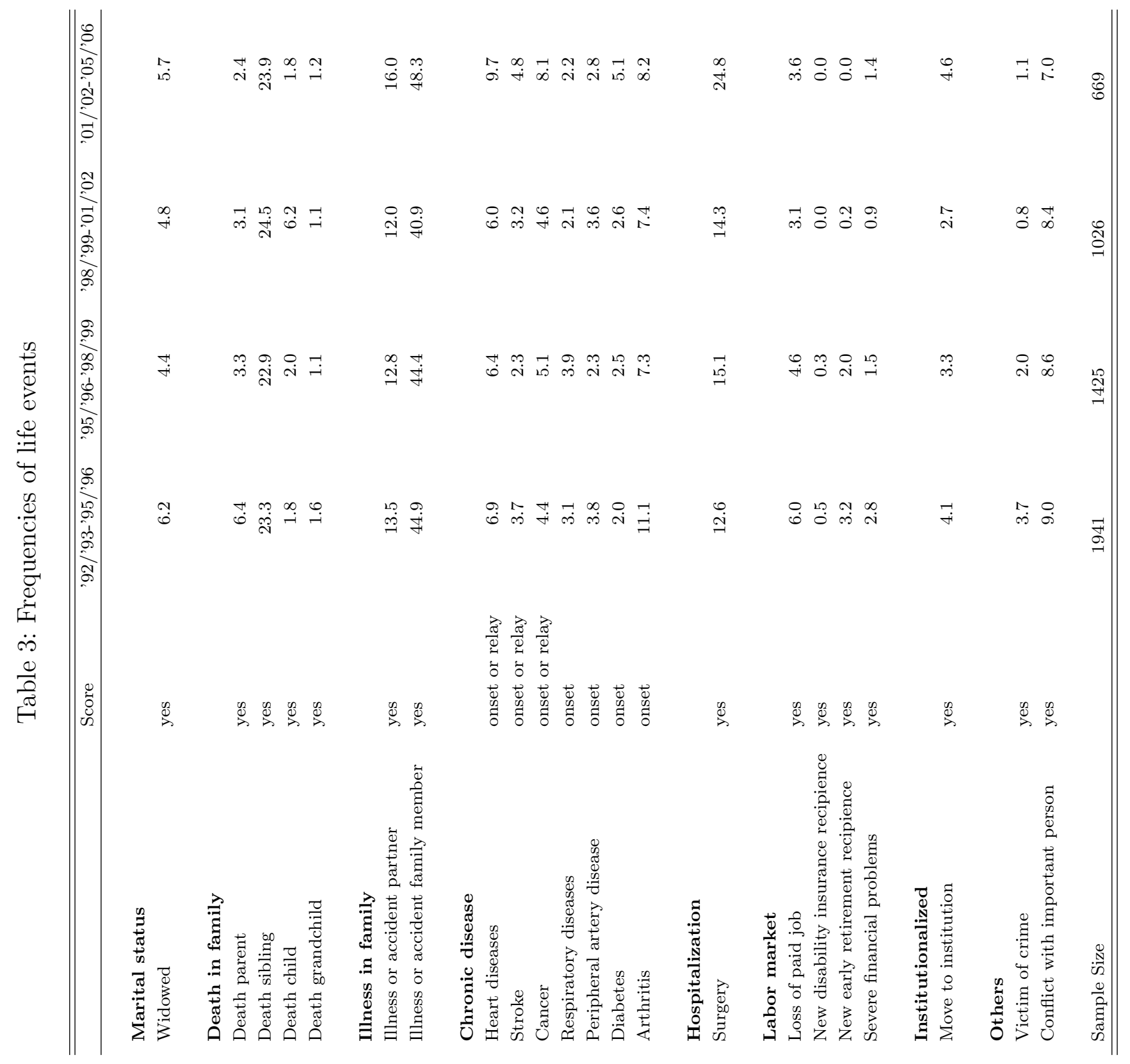




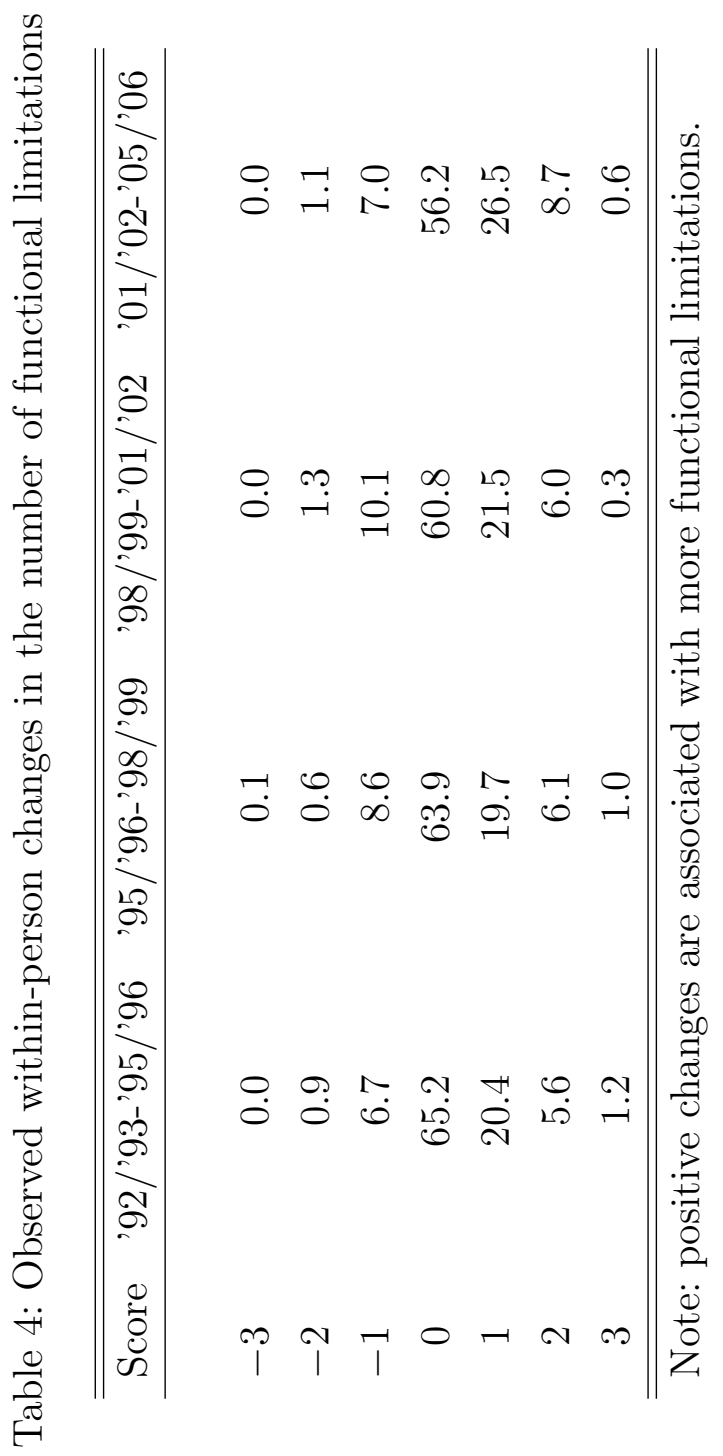


Table 5: Effects of a birth in a recession on functional limitations by cycle of birth (Levels equation)

\begin{tabular}{lllll}
\hline \hline & \multicolumn{2}{c}{ Cycle I } & \multicolumn{2}{c}{ Cycle II } \\
& Est. & S.e. & Est. & S.e. \\
\hline \multirow{2}{*}{$\begin{array}{lllll}\text { Business cycle conditions } \\
\text { Recession }\end{array}$} & & & & \\
& $.219 * * *$ & .077 & $.301 * * *$ & .067 \\
Background characteristics & & & & \\
Male & & & & \\
Age & $-.647 * * *$ & .062 & $-.320 * * *$ & .065 \\
& $.102 * * *$ & .007 & $.093 * * *$ & .005 \\
\# observations & & & & \\
\hline \hline
\end{tabular}

Notes: ${ }^{*} \mathrm{p}<0.1,{ }^{* *} \mathrm{p}<0.05,{ }^{* * *} \mathrm{p}<0.01$. S.e.'s clustered by individual. Estimated by ordered probit. Cycle I corresponds to birth years 1909-1921 and Cycle II to 1924-1936. Wave specific binary indicators for attrition due to either mortality or remaining reasons are included in the model but omitted from the table. Positive estimates are associated with more functional limitations. 
Table 6: Functional limitations related to a recession at birth, adverse life events and background characteristics by cycle of birth (Levels equation)

\begin{tabular}{|c|c|c|c|c|}
\hline & \multicolumn{2}{|c|}{ Cycle I } & \multicolumn{2}{|c|}{ Cycle II } \\
\hline & Est. & S.e. & Est. & S.e. \\
\hline \multicolumn{5}{|l|}{ Business cycle conditions } \\
\hline Recession & $.193 *$ & .108 & $.275 * * *$ & .076 \\
\hline \multicolumn{5}{|l|}{ Adverse life events } \\
\hline Chronic diseases & $.319 * * *$ & .062 & $.286 * * *$ & .050 \\
\hline Widowed & -.119 & .112 & -.134 & .114 \\
\hline Death family member & .002 & .067 & .058 & .053 \\
\hline Illness or accident partner & -.067 & .099 & $.189 * * *$ & .069 \\
\hline \multicolumn{5}{|l|}{ Background characteristics } \\
\hline Age & $.093 * * *$ & .010 & $.089 * * *$ & .007 \\
\hline Education medium & $-.189 *$ & .097 & -.041 & .078 \\
\hline Education high & -.188 & .117 & $-.411 * * *$ & .122 \\
\hline Male & $-.556 * * *$ & .087 & $-.301 * * *$ & .074 \\
\hline Married & -.002 & .094 & $-.162 * *$ & .080 \\
\hline Urbanized medium & .102 & .142 & $.193 *$ & .106 \\
\hline Urbanized high & .082 & .130 & .082 & .099 \\
\hline \# observations & 1456 & & 2790 & \\
\hline
\end{tabular}

Notes: ${ }^{*} \mathrm{p}<0.1,{ }^{* *} \mathrm{p}<0.05, * * * \mathrm{p}<0.01$. S.e.'s clustered by individual. Estimated by ordered probit. Cycle I corresponds to birth years 1909-1921 and Cycle II to 1924-1936. Wave specific binary indicators for attrition due to either mortality or remaining reasons are included in the model but omitted from the table. Positive estimates are associated with more functional limitations. 
Table 7: Effects of a birth in a recession on the number of adverse life events by cycle of birth

\begin{tabular}{|c|c|c|c|c|c|}
\hline \multirow[t]{2}{*}{ Outcome } & \multirow[t]{2}{*}{ Variable } & \multicolumn{2}{|c|}{ Cycle I } & \multicolumn{2}{|c|}{ Cycle II } \\
\hline & & Est. & S.e. & Est. & S.e. \\
\hline Chronic diseases & recession & .029 & .103 & .066 & .067 \\
\hline Widowed & recession & .129 & .149 & $-.284 * * *$ & .108 \\
\hline $\begin{array}{l}\text { Death family } \\
\text { member }\end{array}$ & recession & -.019 & .111 & .036 & .071 \\
\hline $\begin{array}{l}\text { Illness or accident } \\
\text { partner }\end{array}$ & recession & -.173 & .155 & .037 & .088 \\
\hline \# observations & & 1456 & & 2790 & \\
\hline
\end{tabular}

Notes: ${ }^{*} \mathrm{p}<0.1,{ }^{* *} \mathrm{p}<0.05,{ }^{* * *} \mathrm{p}<0.01$. S.e.'s clustered by individual within brackets. Estimated by binary probit. Cycle I corresponds to birth years 1909-1921 and Cycle II to 1924-1936. Controls for age, gender and wave specific binary indicators for attrition due to either mortality or remaining reasons are included in the model but omitted from the table. 
Table 8: Effects of adverse life events and their interactions with recessions at birth on functional limitations (First-differenced equation)

\begin{tabular}{|c|c|c|}
\hline & Est. & S.e. \\
\hline Chronic diseases & $.086 * *$ & .037 \\
\hline $\begin{array}{l}\text { Interact. recession and } \\
\text { chronic diseases }\end{array}$ & $.105 * *$ & .047 \\
\hline Widowed & .061 & .084 \\
\hline $\begin{array}{l}\text { Interact. recession and } \\
\text { widowed }\end{array}$ & -.013 & .116 \\
\hline Death family member & .024 & .037 \\
\hline $\begin{array}{l}\text { Interact. recession and } \\
\text { death family member }\end{array}$ & -.026 & .044 \\
\hline $\begin{array}{l}\text { Illness or accident partner } \\
\text { Interact. recession and } \\
\text { illness or accident partner }\end{array}$ & $\begin{array}{r}.045 \\
-.016\end{array}$ & $\begin{array}{l}.049 \\
.062\end{array}$ \\
\hline \# observations & 4410 & \\
\hline \multicolumn{3}{|c|}{$\begin{array}{l}\text { Notes: }{ }^{*} \mathrm{p}<0.1,{ }^{* *} \mathrm{p}<0.05,{ }^{* * *} \mathrm{p}<0.01 \text {. S.e.'s clustered } \\
\text { by individual. Estimated by OLS. Positive estimates are } \\
\text { associated with more functional limitations. Controls for } \\
\text { age, age }^{2} \text {, the remaining life events, a constant and the } \\
\text { wave and sample dummies are included in the model but } \\
\text { omitted from the table. }\end{array}$} \\
\hline
\end{tabular}


Table 9: Effects of adverse life events and their interactions with recessions at birth on functional limitations by gender (First-differenced equation)

\begin{tabular}{|c|c|c|c|c|}
\hline & \multicolumn{2}{|c|}{ Males } & \multicolumn{2}{|c|}{ Females } \\
\hline & Est. & S.e. & Est. & S.e. \\
\hline Chronic diseases & $.087 *$ & .052 & .084 & .053 \\
\hline $\begin{array}{l}\text { Interact. recession and } \\
\text { chronic diseases }\end{array}$ & $.111 *$ & .064 & .095 & .068 \\
\hline Widowed & -.163 & .143 & .149 & .104 \\
\hline $\begin{array}{l}\text { Interact. recession and } \\
\text { widowed }\end{array}$ & .058 & .203 & -.065 & .140 \\
\hline Death family member & .043 & .057 & .009 & .049 \\
\hline $\begin{array}{l}\text { Interact. recession and } \\
\text { death family member }\end{array}$ & -.050 & .065 & .001 & .061 \\
\hline Illness or accident partner & $.141 * *$ & .067 & -.090 & .070 \\
\hline $\begin{array}{l}\text { Interact. recession and } \\
\text { illness or accident partner }\end{array}$ & -.100 & .086 & .061 & .089 \\
\hline \# observations & 2034 & & 2376 & \\
\hline $\begin{array}{l}\text { Notes: }{ }^{*} \mathrm{p}<0.1,{ }^{* *} \mathrm{p}<0.05 \\
\text { mated by OLS. Positive es } \\
\text { tations. Controls for age, a } \\
\text { wave and sample dummies } \\
\text { table. }\end{array}$ & $\begin{array}{l}\mathrm{p}<0.01 . \mathrm{s} \\
\text { tes are ass } \\
\text { the remair } \\
\text { included ir }\end{array}$ & $\begin{array}{l}\text { e.'s clu } \\
\text { ciated } \\
\text { ng life } \\
\text { the m }\end{array}$ & $\begin{array}{l}\text { by indi } \\
\text { nore fun } \\
\text {, a cons } \\
\text { it omitt }\end{array}$ & $\begin{array}{l}\text { l. Esti- } \\
\text { aal limi- } \\
\text { and the } \\
\text { om the }\end{array}$ \\
\hline
\end{tabular}


Table 10: Fixed effects regressed on indicators of business cycle conditions at birth and background characteristics

\begin{tabular}{|c|c|c|}
\hline & Est. & S.e. \\
\hline \multicolumn{3}{|c|}{$\begin{array}{l}\text { Business cycle conditions } \\
\text { at birth }\end{array}$} \\
\hline Recession & .017 & .037 \\
\hline \multicolumn{3}{|c|}{ Background characteristics } \\
\hline Year of birth & $-.032 * * *$ & .003 \\
\hline Education middle & $-.100 * *$ & .042 \\
\hline Education higher & $-.131 * *$ & .054 \\
\hline Male & $-.286 * * *$ & .038 \\
\hline Married & $-.165 * * *$ & .044 \\
\hline Urbanization middle & .041 & .054 \\
\hline Urbanization high & .040 & .050 \\
\hline Chronic disease & $.472 * * *$ & .036 \\
\hline Constant & $62.005 * * *$ & 4.844 \\
\hline \# Observations & 1780 & \\
\hline \multicolumn{3}{|c|}{$\begin{array}{l}\text { Notes: }{ }^{*} \mathrm{p}<0.1,{ }^{* *} \mathrm{p}<0.05,{ }^{* * *} \mathrm{p}<0.01 . \text { Robust s.e.'s } \\
\text { are included. The calculated fixed effects from the main } \\
\text { regression are included as dependent variable. High val- } \\
\text { ues are associated with large numbers of functional li- } \\
\text { mitations. }\end{array}$} \\
\hline
\end{tabular}


Table 11: Effects of adverse life events and their interactions with the cyclical value of the HP-filter at birth on functional limitations (First-differenced equation)

\begin{tabular}{|c|c|c|}
\hline & Est. & S.e. \\
\hline Chronic diseases & $.148 * * *$ & .027 \\
\hline $\begin{array}{l}\text { Interact. cyclical value and } \\
\text { chronic diseases }\end{array}$ & $-1.318 * * *$ & .346 \\
\hline Widowed & .053 & .059 \\
\hline $\begin{array}{l}\text { Interact. cyclical value and } \\
\text { widowed }\end{array}$ & .447 & .664 \\
\hline Death family member & .009 & .025 \\
\hline $\begin{array}{l}\text { Interact. cyclical value and } \\
\text { death family member }\end{array}$ & $.482 *$ & .278 \\
\hline $\begin{array}{l}\text { Illness or accident partner } \\
\text { Interact. cyclical value and } \\
\text { illness or accident partner }\end{array}$ & $\begin{array}{l}.037 \\
.091\end{array}$ & $\begin{array}{l}.032 \\
.412\end{array}$ \\
\hline \# observations & 4410 & \\
\hline \multicolumn{3}{|c|}{$\begin{array}{l}\text { Notes: }{ }^{*} \mathrm{p}<0.1,{ }^{* *} \mathrm{p}<0.05,{ }^{* * *} \mathrm{p}<0.01 . \text { S.e.'s clustered } \\
\text { by individual. Estimated by OLS. Positive estimates are } \\
\text { associated with more functional limitations. Controls for } \\
\text { age, age }{ }^{2} \text {, the remaining life events, a constant and the } \\
\text { wave and sample dummies are included in the model but } \\
\text { omitted from the table. }\end{array}$} \\
\hline
\end{tabular}


Table 12: Effects of adverse life events and their interactions with births in troughs of business cycles on functional limitations (First-differenced equation)

\begin{tabular}{|c|c|c|}
\hline & Est. & S.e. \\
\hline Chronic diseases & $.091 * * *$ & .031 \\
\hline $\begin{array}{l}\text { Interact. trough and } \\
\text { chronic diseases }\end{array}$ & $.171 * * *$ & .054 \\
\hline Widowed & .062 & .073 \\
\hline $\begin{array}{l}\text { Interact. trough and } \\
\text { widowed }\end{array}$ & -.024 & .120 \\
\hline Death family member & .031 & .030 \\
\hline $\begin{array}{l}\text { Interact. trough and } \\
\text { death family member }\end{array}$ & -.066 & .045 \\
\hline $\begin{array}{l}\text { Illness or accident partner } \\
\text { Interact. trough and } \\
\text { illness or accident partner }\end{array}$ & $\begin{array}{r}.044 \\
-.018\end{array}$ & $\begin{array}{l}.040 \\
.061\end{array}$ \\
\hline \# observations & 4410 & \\
\hline \multicolumn{3}{|c|}{$\begin{array}{l}\text { Notes: }{ }^{*} \mathrm{p}<0.1,{ }^{* *} \mathrm{p}<0.05,{ }^{* * *} \mathrm{p}<0.01 . \text { S.e.'s clustered } \\
\text { by individual. Estimated by OLS. Positive estimates are } \\
\text { associated with more functional limitations. Controls for } \\
\text { age, } \text { age }^{2} \text {, the remaining life events, a constant and the } \\
\text { wave and sample dummies are included in the model but } \\
\text { omitted from the table. }\end{array}$} \\
\hline
\end{tabular}




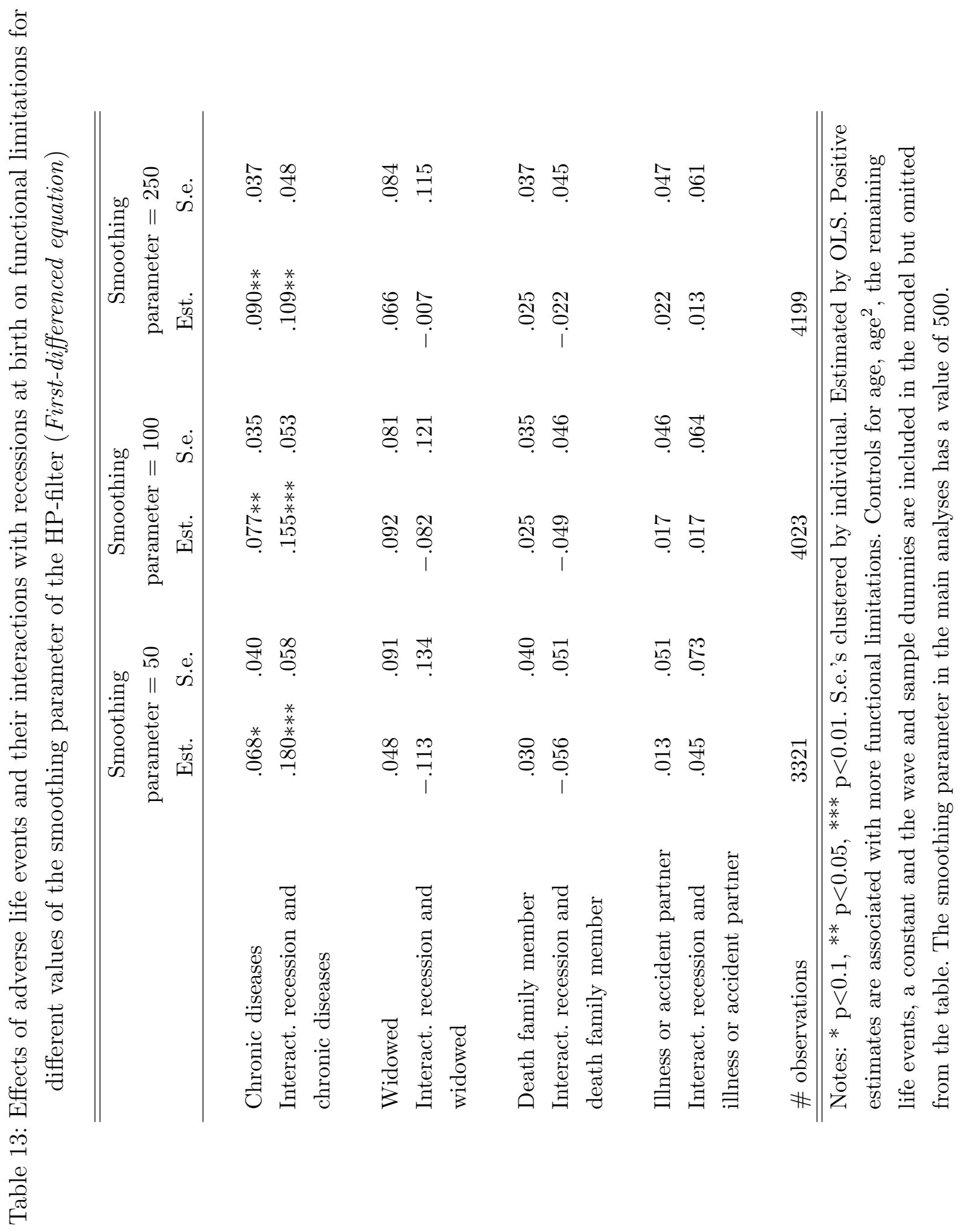


Table 14: Effects of the specific chronic diseases and their interactions with recessions at birth on functional limitations (First-differenced equation)

\begin{tabular}{lcc}
\hline \hline & Est. & S.e. \\
\hline & & \\
Chronic diseases & & \\
Respiratory & .170 & .122 \\
Interact. recession and respiratory & -.046 & .151 \\
Peripheral artery & $.282 * *$ & .111 \\
Interact. recession and peripheral artery & $-.276 *$ & .149 \\
Arthritis & .071 & .064 \\
Interact. recession and arthritis & $.163 * *$ & .082 \\
Stroke & .077 & .100 \\
Interact. recession and stroke & .158 & .137 \\
Heart & .057 & .069 \\
Interact. recession and heart & .104 & .093 \\
Cancer & -.068 & .080 \\
Interact. recession and cancer & $.224 * *$ & .106 \\
Diabetes & .124 & .128 \\
Interact. recession and diabetes & -.226 & .170 \\
& & \\
Remaining adverse life events & & \\
Widowed & .0648 & .049 \\
Interact. recession and widowed & -.021 & .062 \\
Death family member & & \\
Interact. recession and death family member & -.018 & .044 \\
Illness or accident partner & .020 & .115 \\
Interact. recession and illness or accident partner & -.021 \\
\# observations & & \\
\hline \hline
\end{tabular}

Notes: ${ }^{*} \mathrm{p}<0.1,{ }^{* *} \mathrm{p}<0.05,{ }^{* * *} \mathrm{p}<0.01$. S.e.'s clustered by individual. Estimated by OLS. Positive estimates are associated with more functional limitations. Controls for age, age $^{2}$, the remaining life events, a constant and the wave and sample dummies are included in the model but omitted from the table. 